\title{
Monitoring toxic pollutants for better air quality
}

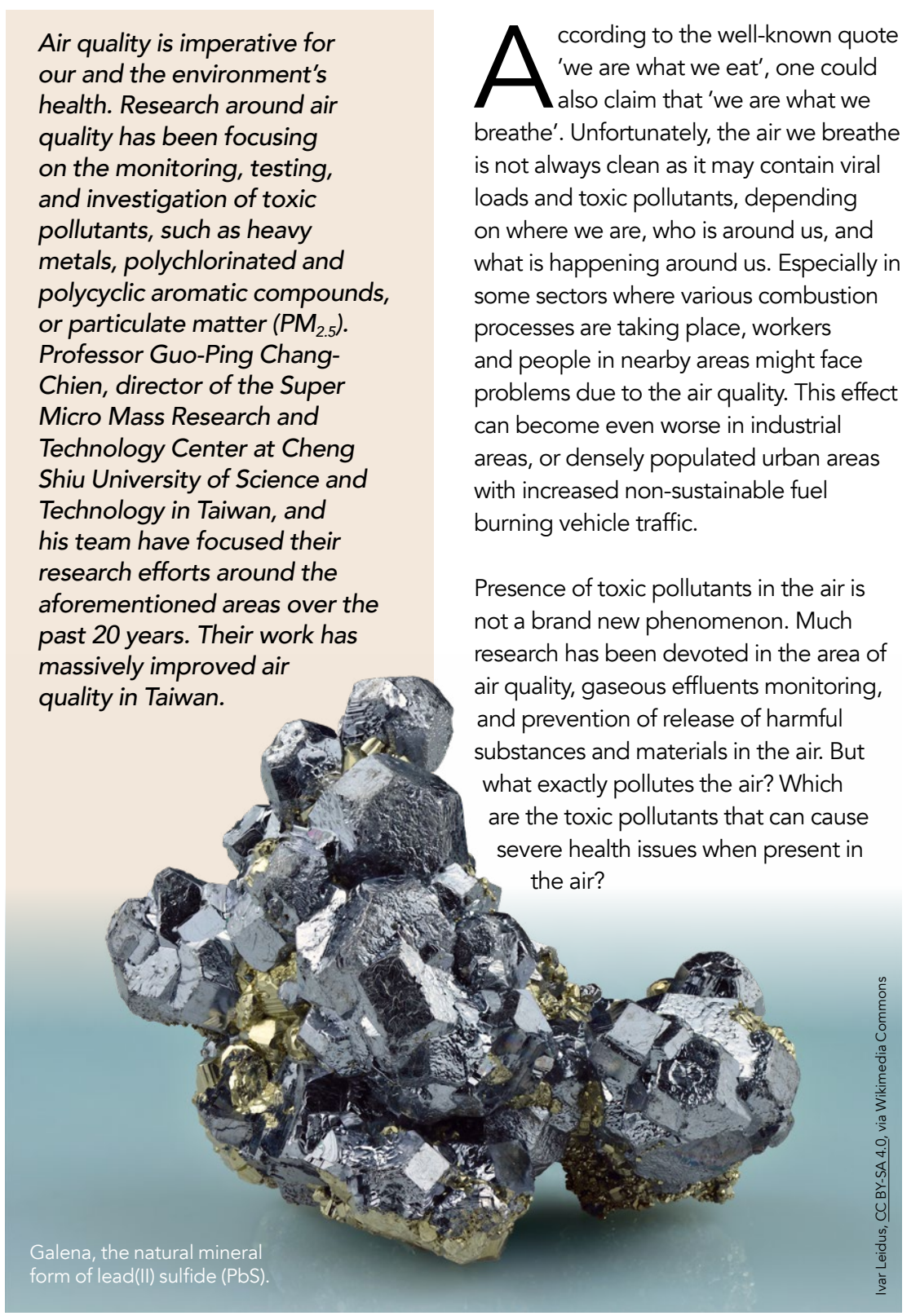

\section{THE LEXICON OF}

\section{TOXIC POLLUTANTS}

Con

Combustion, scientifically known as the rapid combination of substance with oxygen that results in production of heat, light, and gaseous products, is basically the process of burning something. Combustion usually refers to burning of fossil fuels like coal or petrol, or biomass like wood or dry woody plant parts. One way or another, we have all been exposed to an open fire outdoors or car fumes, and we probably tried to avoid the smoke associated with the process.

Toxic pollutants present in smoke are derived from various combustion processes. These pollutants are not concentration, and combination highly depend on the substance that is being burnt and the conditions of combustion Toxic pollutants present in gas streams associated with combustion can, among others, include heavy metals, polycyclic aromatic compounds, polychlorinated or polybrominated compounds, and particulate matter. Heavy metals are usually associated with industrial

combustion, for example within the steel industry, and can comprise of lead (Pb), mercury ( $\mathrm{Hg})$, chromium (Cr), cadmium (Cd), and arsenic (As). Polychlorinated compounds can include polychlorinated dibenzzo dioxin (PCDDs), polychlorinated dipenzenyl ethers (PCDEs), and polychlorinated dibenzofurans (PCDFs),

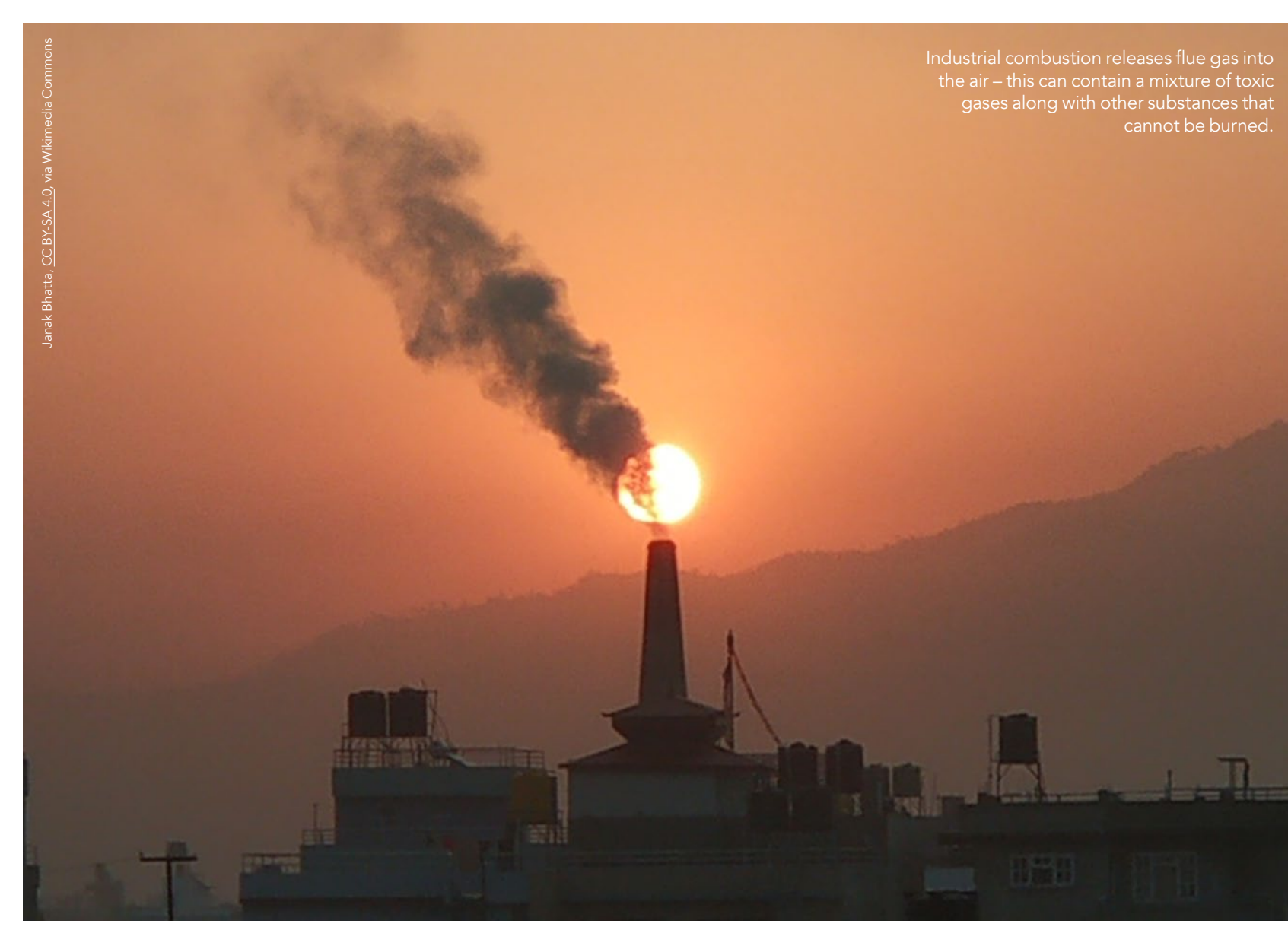

and these are often associated with Flue gas has been a major issue for combustion. Similarly, for polybrominated chemical plants as it is the equivalent compounds, the most important category of exhaust fumes for cars, but in a is polybrominated diphenyl ethers (PBDEs). Last but definitely not least, another toxic pollutant often found in Controlling the quality of flue gas and specifically, monitoring the concentration

Restriction of vehicle idling reduced emissions of $P M_{2.5}, P M_{0.1}, P A H s$ and black carbon levels.

Particulate matter are tiny solid or liquid solid particles with a diameter me in microns (one millionth of a meter). An often used standard size for particulate matter is a diameter of 2.5 microns $\mathrm{PM}_{25}$.). At that size or lower, particles can penetrate deep into lungs and cause severe health issues.

TOXIC POLLUTANTS IN FLUE GAS Flue gas is the technical term used for the exhaust products during industrial combustion. Il can contain a mixture all toxic pollutants mentioned earlier, along with residual fuel and residual environment is of imperative importan especially in the last few years that environmental and health protection

Professor Guo-Ping Chang-Chien, director of the Super Micro Mass Research and Technology Center at Cheng Sh University, Taiwan, and his research team have been focusing their efforts in the area of monitoring and controlling toxic pollutants in flue gas and other combustion gases. For the past 20 yea the researchers have focused on toxic pollutants in flue gas emissions includ
dioxins, PCBs, polycyclic aromatic compounds, heavy metals, and $\mathrm{PM}_{25}$. Because of the testing and investigation local local industries with the Super Micro Mass Research and Technology Center, Taiwa has attained a $90 \%$ overall reduction of

A recent publication by researchers associated with the Super Micro Mass Research and Technology Center on the produced from coal burning boilers and sintering furnaces in a steel production plant highlighted the reduction in toxic pollutants present in effluents. Pollutants' reduction was attributed to the implementation of available air pollution control devices (APCD) as a step before the release of flue gas into the atmosphere. This research focused on the examination of emission factors (EFs) of toxic pollutants, as they were calculated via field investigations and laboratory experiments, rather than following the available EF guideline from the Taiwan Environmental Protection Agency (EPA), as the standard values the true picture. Emission factors, a 


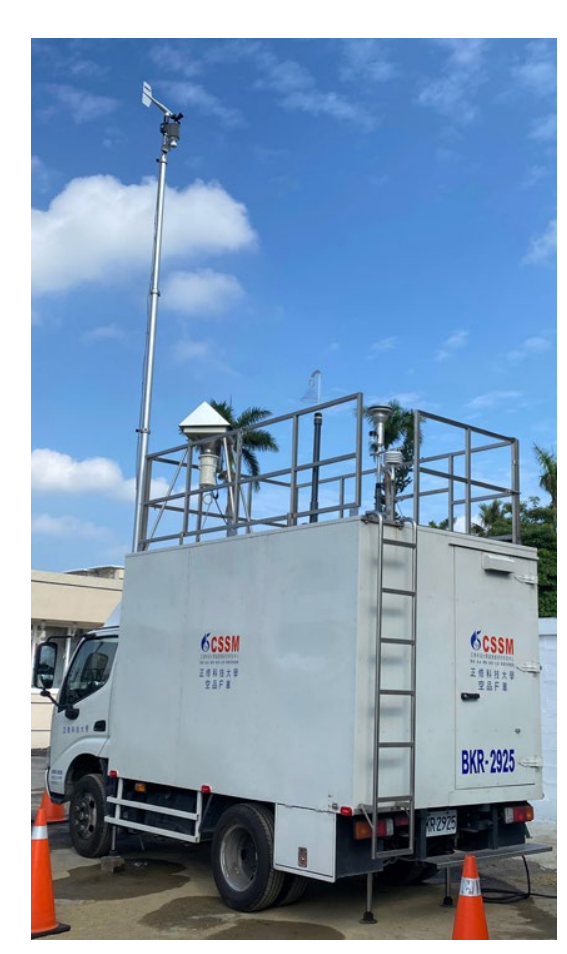

The Center's mobile air quality monitoring

common index for emission estimation, correspond to the weight of pollutant per unit of product, or per duration of the activity that emits the pollutant, and they are used to measure potentially toxic emissions.

\section{RESEARCHING EMISSION FACTORS} FOR TOXIC POLLUTANTS

Focusing on a steel production plant, the researchers set up a sampling sys for the collection of effluent samples from coal-fired boilers and sintering
furnaces, with the collection point being furnaces, with the collection point being after the APCD, and analysed those It was shown that obtained results from field investigations were considerably lower than emission factors set by EPA, a fact that could indicate overcharging of plants for this particular issue, even if plants are equipped with state-of-the-art APCD.

In a different research project, Professor Chang-Chien investigated the

emission factors of polychlorinated and polybrominated compounds during rice straw biomass burning in fields. Air samples were collected from three different points during burning periods and non-burning periods and analysed for concentration OFCDDs and PBDEs. Results showed that during burning

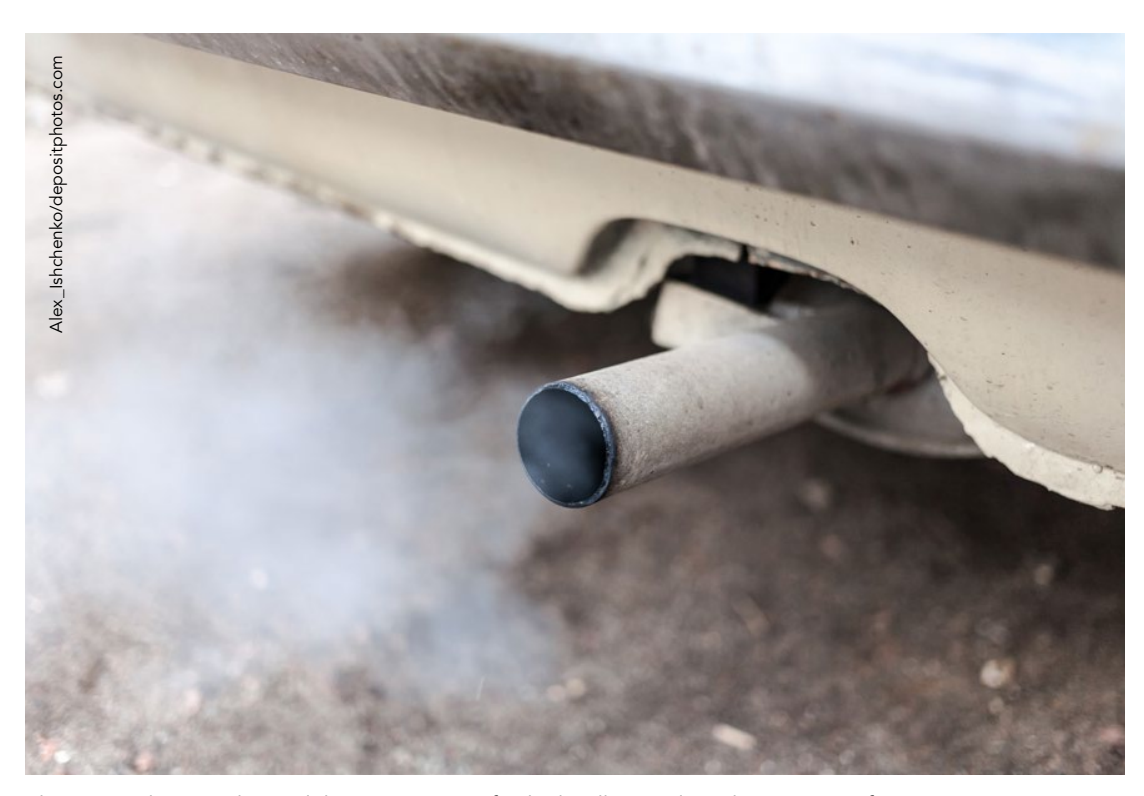

The research team showed that restriction of
$\mathrm{PM}_{25}, \mathrm{PM}_{0,1}, \mathrm{PAH}_{\mathrm{H}}$, and black carbon levels.

toxic pollutants was much larger than during non-burning periods, especially close to the burning site. It was sho that the emission factor for PBDEs was almost 19 times higher than that for PCDDs. Interestingly, looking at the composition of rice straw, PBDEs were not originally present, which leads to the fact that they were synthesised during combustion. The production of PBDEs during rice straw burning in op fields and the high emission factor of this toxic pollutant indicated that this phenomenon should not be neglected. Touching on the emission factors of $P M, M_{2.5}$ specifically, researchers from the Super Micro Mass Research and mobile sampling for spatial analysis ofemission factors, and analysis of contribution of various emission sou towards the $\mathrm{PM}_{25}$ emission factor. Results showed that restriction of vehic idling reduced emissions of $\mathrm{PM}_{25}, \mathrm{PM}_{0}$ PAHs, and black carbon levels, with PAHs showing the highest reduction, by almost 50\%.

\section{MONITORING THE AIR QUALITY} The highlighted research examples from Professor Chang-Chien and Technology Center showcase that collaboration between industry and spectacular break can lad to spectacular breaktrough, in this case modelling in order to calculate the the Super Micro Mass Research and

The highlighted research examples showcase that collaboration between industry and research institutions can

lead to spectacular breakthrough.

running engine but not in motion) could make in air quality around a school site. They monitored the concentratons of toxic pollutants such as $\mathrm{PM}_{2.5}$, Polycyclic Aromatic Hydrocarbons (PAHs), and black carbon at normal conditions and When illing vehicles were resticted in the surrounding area. The sampling is imperative, as what we breathe affects our health and can contribute to environmental concerns. Through adoption of APCD and implementation of emission control regulations, the be monitored and reduced, leading to overall improved air quality. testing and investigation, as well as

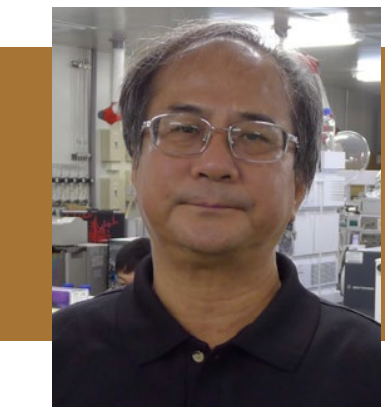

Behind the Research

\section{Professor Guo-Ping Chang-Chien}

E: guoping@gcloud.csu.edu.tw T: +88677358800 \#3042 W: http://cssm.csu.edu.tw/wSite/mp?mp=cssm YouTube: https://www.youtube.com/watch?v=4ZFFrbbFHhg

\section{Research Objectives}

Professor Chang-Chien and his team study different toxic pollutants: specifically, dioxins, polychlorinated biphenyls (PCBs), polycyclic aromatic compounds, heavy metals, and $\mathrm{PM}_{2 .}$

\section{Detail}

Super Micro Mass Research and Technology Center Cheng Shiu University

833301 No. 840, Chengcing Road,

Niaosong District, Kaohsiung City/

Bio

For the past 20 years, researchers at the Super Micro Mass Research and Technology Center have focused on toxic pollutants in flue gas emissions including dioxins, polychlorinated biphenyls (PCBs), polycyclic aromatic compounds, heavy metals, and $\mathrm{PM}_{25}$. Taiwan has attained a $90 \%$ overall reduction of dioxin concentration in the past 20 years, and under the guidance of the director, Professor Guo-Ping Chang-Chien, the Center offered very instrumental services of testing and investigations.

Funding

Environmental Protection Bureau, Chiayi City, Taiwan

- China Steel Corporation, Kaohsiung, Taiwan, R.O.C. Ministry of Science and Technology, Taiwan, R.O.C

\section{Collaborators}

DrHsin-Chieh Kun

DrYen-Yi Lee

Dr Justus Kavita Mutuku

National Cheng Kung University, Department of Environmental Engineering \& Department of Environmental and Occupational Health Environmental Engineering

\section{References}

Mutuku, JK, Lee, YY, Huang, BW, Chen, WH, Hou, WC, (2021) Assessment of the emission factors for potentially toxic elements from coal-fired boilers and sintering furnaces https://doi.org/10.1016/.jscitotenv.2021.148329

Lee, YY, Lin, SL, Yuan, CS, Lin, ML, Chen, KS, (2018) Reduction of atmospheric fine particle level by restricting the idling vehicles around a sensitive area. J. Air Waste Manag. 018.1438320

Chang, SS, Lee, WJ, Holsen, TM, Li, HW, Wang, LC, ChangChien, GP, (2014) Emissions of polychlorinated-p-dibenzo dioxin, dibenzofurans (PCDD/Fs) and polybrominated diphenyl ethers (PBDEs) from rice straw biomass burning. atmosenv.2014.05.067

\section{Personal Response}

Can findings from this research form the basis of new policy implementation, e.g., controlled around schools, etc.?

II Yes, the findings from this research can be applied as a basis for new policy implementation. For instance, industria plants equipped with APCDs could be encouraged to pay air pollution fees for the emission of potentially toxic the Defalt EFs from respective environmental protection agencies. This will help industrial companies to save money and, ultimately, encourages them to install and maintain APCDs. Idling of vehicles, especially those with diesel. engines, could be limited to a certain number of minutes in crowded places in order to lower the concentrations of ambient air $\mathrm{PM}_{2,5}$.

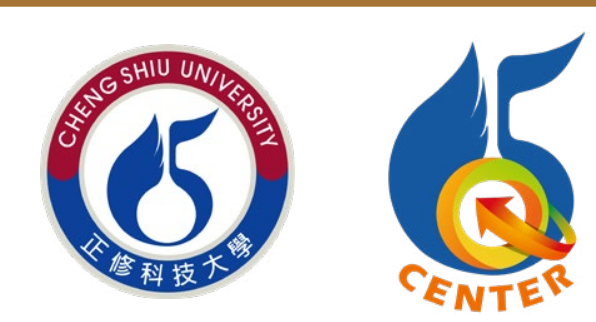

